\title{
Avaliação da Proporção de Fases em Juntas Soldadas de Tubulações de Aço Inoxidável Duplex Mediante Aplicação de Ensaios Não Destrutivos
}

\author{
(Evaluation of Phases Proportions in Welded Joints of Duplex Stainless Steel by Non-Destructive Testing)
}

\author{
Guttemberg Chagas de Souza ${ }^{1}$, Juan Manuel Pardal ${ }^{1}$, Sérgio Souto Maior Tavares ${ }^{1}$, Maria da Penha Cindra Fonseca ${ }^{1}$, Jose Luiz \\ Ferreira Martins ${ }^{1}$, Elineudo Pinho de Moura ${ }^{2}$, Ismael Cardote Filho ${ }^{3}$ \\ ${ }^{1}$ Universidade Federal Fluminense /Programa de Pós graduação em Engenharia Mecânica (PGMEC), Niterói, Rio de Janeiro, \\ Brasil,guttemberg.souza@uol.com.br \\ ${ }^{2}$ Universidade Federal do Cearál Depto de Eng ${ }^{a}$ Metalúrgica e Materiais, Fortaleza, Ceará, Brasil. \\ ${ }^{3}$ UTC Engenharia S/A, Niterói, Rio de Janeiro, Brasil
}

\begin{abstract}
Resumo
Os aços inoxidáveis Duplex (AID) aliam uma excelente resistência à corrosão com elevada resistência mecânica devido à fina microestrutura bifásica composta por quantidades similares de ferrita $(\delta)$ e austenita $(\gamma)$. Portanto, estas ligas são utilizados em tubulações e equipamentos industriais onde se requer elevada relação resistência/peso, especialmente em empreendimentos de construção e montagem off-shore. Entretanto, as condições operacionais, na soldagem de campo, podem promover um significativo desbalanço microestrutural destas fases, resultando em decréscimo das propriedades mencionadas. A inspeção com o ferritoscópio é uma avaliação normalmente utilizada nestas atividades. Durante a avaliação com esta técnica pode ocorrer a rejeição da junta soldada quando o metal de solda se encontra com valores de ferrita fora das faixas estabelecidas pelas especificações de projeto. Assim, tornase importante a análise destas juntas, com outras técnicas complementares, tal como a utilização das réplicas metalográficas. Este fato motivou a avaliação da proporção de fases em spools de AID de espessuras relativamente finas, soldados no campo, comparando-se as técnicas não destrutivas descritas. Os resultados denotam valores semelhantes, contudo o resultado pode ser influenciado pela forma e condições superficiais da junta soldada.
\end{abstract}

Palavras-Chave: Aço Inoxidável duplex; Soldagem. Ensaios Não-Destrutivos; Propriedades magnéticas; Réplicas metalográficas.

\begin{abstract}
Duplex stainless steels are high strength and corrosion resistant alloys, whose properties are devoted to the fine microstructure composed by similar amounts of ferrite and austenite and also to the high concentrations of $\mathrm{Cr}, \mathrm{Mo}$ and $\mathrm{N}$ in solid solution. Not for coincidence, duplex steels are extensively used in chemical and petrochemical industries. However, welding operations conditions can promote the unbalance of the ferrite/austenite proportions mainly in the welding metal, with decrease of the properties mentioned. For this reason, non destructive measurements of ferrite content, by ferritoscope, is used after welding pipes. Ferritoscope is a commercial instrument which uses the initial magnetic permeability to analyze the ferrite content in duplex and austenitic stainless steels. The inspection with ferritoscope is a procedure commonly used in building and assembly of spools of duplex and superduplex stainless steels. The objective of this work was to evaluate the amounts of phases in the welding metal for different spools welded in the field by use of ferritoscope and metallographic replica techniques. The results showed that the two techniques measured similar values of ferrite and austenite, but ferritoscope analysis can be influenced by shape and surface conditions of the welded joint.
\end{abstract}

Keywords: Duplex Stainless Steel; Welding; Non destructive Testing; Magnetic properties; Metallographic replica

\section{Introdução}

Os aços inoxidáveis Duplex (AID) são aços que aliam uma excelente resistência à corrosão com altos valores de resistência

Trabalho apresentado no CONSOLDA 2012.

Recebido em 22/01/2013. Texto final em 16/03/2013. mecânica devido à fina microestrutura bifásica composta por quantidades similares de ferrita $(\delta)$ e austenita $(\gamma)$ [1]. Atualmente os AID estão sendo utilizados em grande escala na construção de plataformas off-shore, em sistemas de injeção de água salgada, bem como em sistemas de remoção de $\mathrm{CO}_{2}$ e $\mathrm{H}_{2} \mathrm{~S}$ [2]. Entretanto, durante as atividades de soldagem de campo, pode ocorrer, principalmente, um desbalanço das proporções de fases $\delta$ e $\gamma$ dependendo da velocidade de resfriamento da junta conduzindo a um decréscimo da resistência mecânica e corrosão da junta. Por este motivo o teor da fase ferrítica deve estar situado 
entre $30 \%$ e $70 \%$ de acordo com especificações de projeto [3]. Um teor excessivo de ferrita conduzirá à precipitação de nitretos de cromo $\left(\mathrm{Cr}_{2} \mathrm{~N}\right)$ nesta fase, diminuindo a resistência à corrosão do material. Além disso, ocorrerá um decréscimo da tenacidade como conseqüência da austenita precipitada exercer um forte efeito de refino microestrutural. Finalmente, nestas condições haverá um aumento da temperatura de transição dúctil - frágil da junta devido à maior proporção de ferrita de estrutura CCC. Por outro lado, teores de ferrita precipitada inferiores ao $30 \%$ podem ser devido às velocidades de resfriamento muito baixas durante a soldagem podendo conduzir à precipitação de fases intermetálicas tais como sigma, chi e austenita secundaria que interagem em detrimento da tenacidade e resistência à corrosão da junta soldada. Estas duas formas de desbalanço microestrutural devem ser contornadas na soldagem dos aços duplex. Para que não ocorra um teor excessivamente elevado de ferrita, as medidas são a utilização de metal de adição mais rico em Ni, uso de gás de proteção com adição de 1 a 3\% de nitrogênio na soldagem TIG (GTAW) e controle do aporte de calor para que não seja muito baixo. Para se evitar a precipitação de intermetálicos, a principal medida é o controle do aporte de calor, para que não seja excessivamente alto. Recomenda-se aporte de calor entre $0,5 \mathrm{~kJ} . \mathrm{mm}^{-1} \mathrm{e} 2,5 \mathrm{~kJ} . \mathrm{mm}^{-1}$ para a soldagem de aços inoxidáveis duplex [4].

Como controle para inspeção de componentes soldados nesta classe de materiais, as especificações exigem que as medições da fase ferrítica $(\delta)$ sejam realizadas através da técnica que utiliza o ferritoscópio, cujas medições são baseadas na permeabilidade magnética dos materiais [5]. Estas medições foram efetuadas em juntas produzidas no campo, conforme procedimentos de soldagens qualificados levando em consideração os parâmetros mencionados. Este estudo foi efetuado em metais de solda de juntas soldadas que a priori exibiam teores de ferrita próximos do valor limite de $30 \%$. Deste modo, o presente trabalho pretende analisar a confiabilidade da utilização do ferritoscópio para juntas soldadas com teores próximos do valor limite considerado por norma. Para tal, réplicas metalográficas foram realizadas nas juntas estudadas sendo as imagens adquiridas e quantificadas manualmente de acordo com os requisitos da ASTM E562 [6]. Esta técnica de inspeção não destrutiva foi recentemente aplicada de maneira satisfatória na avaliação microestrutural de aços inoxidáveis superduplex (AISD) [7].

Portanto, o objetivo deste trabalho é avaliar as proporções de fases no metal de solda de spools soldados no campo pelo uso de técnicas não destrutivas, empregando-se o ferritoscópio e as réplicas metalográficas. Os resultados apresentaram valores semelhantes levantados por ambas as técnicas, contudo o estudo pode ser influenciada pela forma e condições superficiais da junta soldada. Finalmente, este estudo terá uma grande contribuição tecnológica por meio da utilização destas técnicas de medição, ressaltando particularidades na execução das mesmas.

\section{Materiais e Métodos}

Para a realização deste trabalho foram produzidas juntas soldadas pelo processo GTAW com as mesmas características das utilizadas em spools de tubulações a serem empregadas na construção de plataformas off-shore, utilizando-se aportes de calor controlados entre 1,0 e $1,5 \mathrm{KJ} \cdot \mathrm{mm}^{-1}$. Todos os materiais de base (MB) correspondem à designação de AID UNS S31803 encontrando-se em estado solubilizado. A Tabela 1 apresenta os valores referentes à composição química dos materiais de base empregados para realização das juntas assim como o índice equivalente de resistência ao pite (PRE) de cada componente. A Tabela 2 exibe a composição química do metal de adição (MA) utilizado para todos os casos. As juntas soldadas a serem analisadas foram identificadas como juntas JPF1, JPF2, JPF3 JPF4, JPF5 e JPF6, respectivamente. A Tabela 3 sumariza a identificação dos $\mathrm{MB}$ de acordo com o componente, características dimensionais das juntas estudadas, local de avaliação não destrutiva e características do mesmo.

Tabela 1. Composição química dos MB dos AID analisados.

\begin{tabular}{|c|c|c|c|c|c|c|c|c|c|c|c|}
\hline \multirow{2}{*}{ Id Junta } & \multirow{2}{*}{ Forma } & \multicolumn{9}{|c|}{ Composição química (\% em peso) (Fe balanço) } & \multirow{2}{*}{ PRE } \\
\hline & & $\mathrm{Cr}$ & $\mathbf{N i}$ & Mo & Mn & $\mathbf{S i}$ & $\mathbf{N}$ & $\mathrm{C}$ & $\mathbf{P}$ & $\mathbf{S}$ & \\
\hline \multirow{2}{*}{ JPF1 } & Tubo & 22,440 & 5,710 & 3,120 & 1,340 & 0,380 & 0,172 & 0,014 & 0,023 & 0,001 & 35,488 \\
\hline & Flange & 22,870 & 6,100 & 3,060 & 1,390 & 0,420 & 0,190 & 0,022 & 0,026 & 0,010 & 36,008 \\
\hline \multirow{2}{*}{ JPF2 } & Tubo & 22,440 & 5,710 & 3,120 & 1,340 & 0,380 & 0,172 & 0,014 & 0,023 & 0,001 & 35,488 \\
\hline & Flange & 22,870 & 6,100 & 3,060 & 1,390 & 0,420 & 0,190 & 0,022 & 0,026 & 0,010 & 36,008 \\
\hline \multirow{2}{*}{ JPF3 } & Tubo & 22,310 & 5,200 & 2,830 & 1,340 & 0,360 & 0,193 & 0,019 & 0,023 & 0,001 & 34,737 \\
\hline & Tê & 22,690 & 5,180 & 2,810 & 1,470 & 0,330 & 0,197 & 0,014 & 0,022 & 0,001 & 35,115 \\
\hline \multirow{2}{*}{ JPF4 } & Tubo & 22,700 & 5,350 & 3,170 & 1,070 & 0,500 & 0,170 & 0,018 & 0,026 & 0,001 & 35,873 \\
\hline & Curva & 22,450 & 5,300 & 3,190 & 1,060 & 0,510 & 0,169 & 0,013 & 0,025 & 0,001 & 35,681 \\
\hline \multirow{2}{*}{ JPF5 } & Curva & 22,200 & 5,300 & 3,300 & 1,780 & 0,400 & 0,170 & 0,019 & 0,022 & 0,001 & 35,810 \\
\hline & Redução & 22,300 & 5,800 & 3,100 & 1,380 & 0,300 & 0,180 & 0,017 & 0,022 & 0,001 & 35,410 \\
\hline \multirow{2}{*}{ JPF6 } & Curva & 22,570 & 5,220 & 2,860 & 1,520 & 0,400 & 0,191 & 0,017 & 0,023 & 0,001 & 35,064 \\
\hline & Redução & 22,310 & 5,200 & 2,830 & 1,340 & 0,360 & 0,193 & 0,019 & 0,023 & 0,001 & 34,737 \\
\hline
\end{tabular}


Tabela 2. Composição química do MA utilizado para a soldagem GTAW.

\begin{tabular}{|c|c|c|c|c|c|c|c|c|c|c|c|}
\hline \multirow{2}{*}{ Consumível } & \multirow{2}{*}{ Vareta $\varnothing(\mathbf{m m})$} & \multicolumn{9}{|c|}{ Composição química (\% em peso) (Fe balanço) } & \multirow{2}{*}{ PRE } \\
\hline & & $\mathrm{Cr}$ & $\mathbf{N i}$ & Мo & Mn & $\mathbf{S i}$ & $\mathbf{N}$ & C & $\mathbf{P}$ & $\mathbf{S}$ & \\
\hline \multirow{2}{*}{ ER 2209} & 2,4 & \multirow{2}{*}{23,000} & \multirow{2}{*}{8,630} & \multirow{2}{*}{3,070} & \multirow{2}{*}{1,510} & \multirow{2}{*}{0,470} & \multirow{2}{*}{0,160} & \multirow{2}{*}{0,009} & \multirow{2}{*}{0,018} & \multirow{2}{*}{0,001} & \multirow{2}{*}{35,691} \\
\hline & 3,2 & & & & & & & & & & \\
\hline
\end{tabular}

Tabela 3. Características das juntas estudadas e local de avaliação não destrutiva.

\begin{tabular}{|l|c|c|c|c|}
\hline Junta & Características da Junta & Dimensões (mm) & Local de Análise & Características do Acabamento \\
\hline JPF1 & Flange (MB1) x Tubo (MB2) & $\varnothing=323,9 ; \mathrm{t}=4,6$ & Acabamento & Efetuado com dois passes \\
\hline JPF2 & Flange (MB1) x Tubo (MB2) & $\varnothing=323,9 ; \mathrm{t}=4,6$ & Raiz & ----------- \\
\hline JPF3 & Tubo (MB1) x Tê (MB2) & $\varnothing=88,9 ; \mathrm{t}=5,5$ & Acabamento & Efetuado com dois passes \\
\hline JPF4 & Curva (MB1) x Tubo (MB2) & $\varnothing=60,3 ; \mathrm{t}=5,5$ & Acabamento & Efetuado com dois passes \\
\hline JPF5 & Redução (MB1) x Curva (MB2) & $\varnothing=88,9 ; \mathrm{t}=5,5$ & Acabamento & Efetuado com dois passes \\
\hline JPF6 & Curva (MB1) x Redução (MB2) & $\varnothing=273,1 ; \mathrm{t}=4,2$ & Acabamento & Efetuado com passe único \\
\hline
\end{tabular}

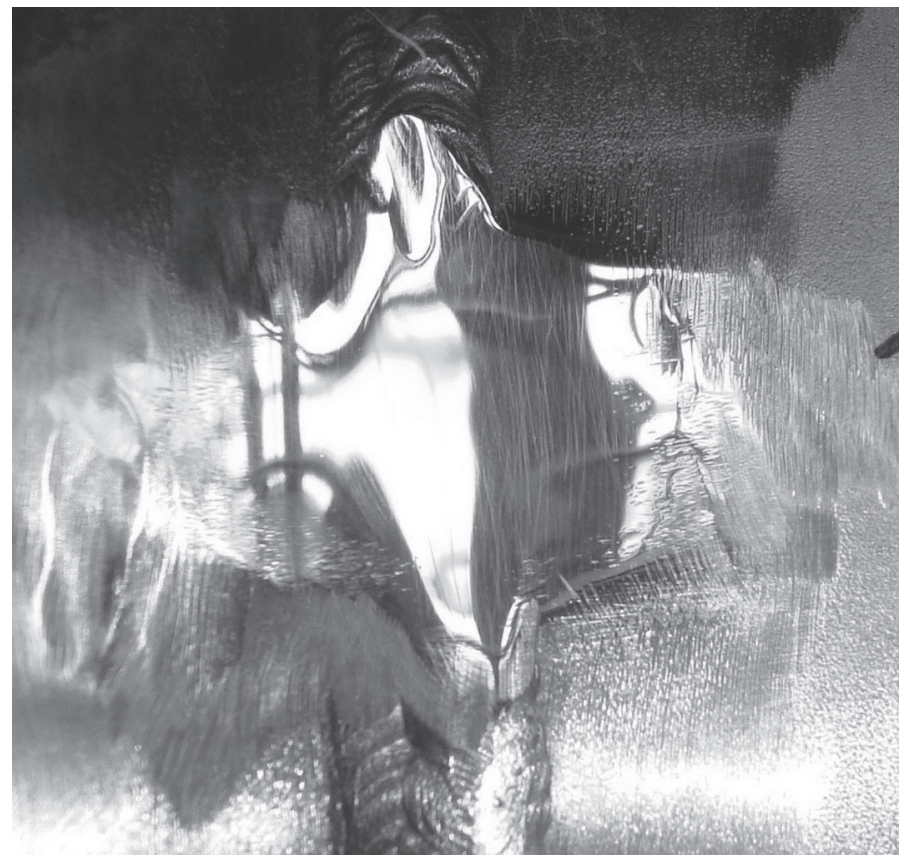

Figura 1. Superfície da junta soldada JPF1 após etapa de polimento.

Após a soldagem, as juntas foram avaliadas através de microscopia ótica indireta (MOI) utilizando réplicas metalográficas para caracterização da microestrutura do metal de solda (MS). Este ensaio também denominado de metalografia de campo é um procedimento não destrutivo em que se realiza a preparação metalográfica por lixamento e polimento in situ. $\mathrm{O}$ ataque metalográfico é também realizado desta forma. Após revelação da microestrutura, aplica-se uma réplica sobre a região preparada. A réplica metalográfica retrata a microestrutura do local que pode ser observada e documentada utilizando-se um microscópio óptico $(\mathrm{MO})$. Para a preparação da superfície, na etapa de lixamento, foram empregadas seqüencialmente uma esmerilhadeira angular e uma microretifica. Com estes equipamentos foi possível atingir o grau de acabamento da superfície com lixa de granulometria 1200. Após limpeza com álcool; sucessivas etapas de polimento foram realizadas com pastas de diamante de 6,3, e $1 \mu \mathrm{m}$. A Figura 1 mostra a superfície da junta soldada JPF1 após etapa de polimento e limpeza final previa à aplicação do reagente.

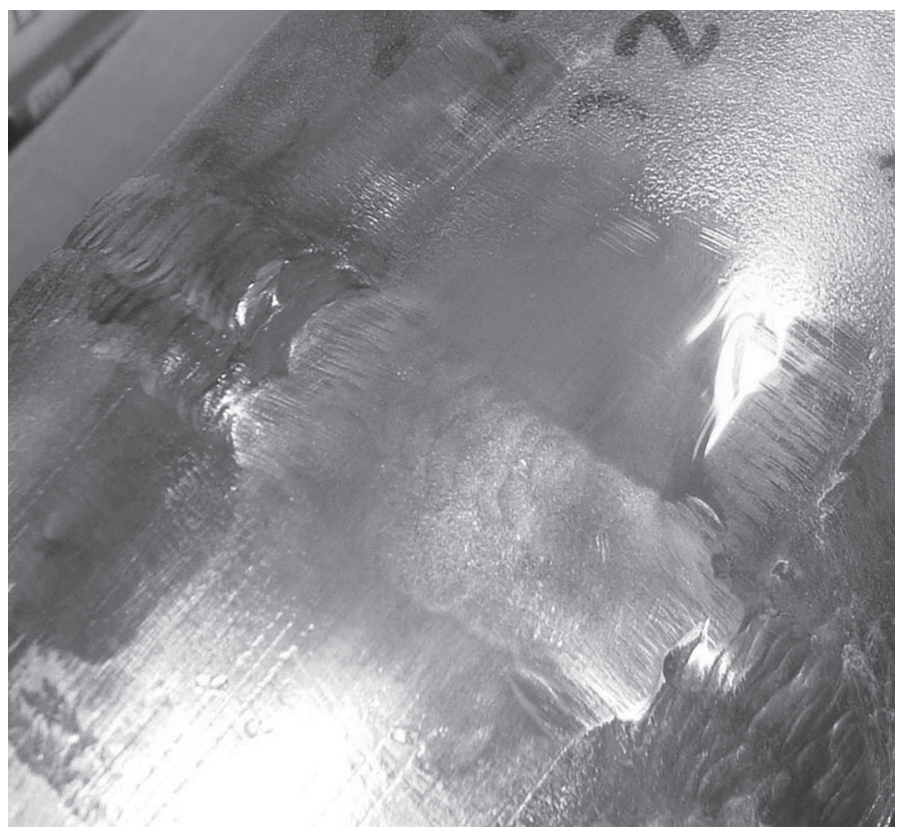

Figura 2. Superfície da junta soldada JPF3 após aplicação do reagente Beraha.

A seguir, o reagente Beraha foi utilizado para revelar a microestrutura in situ das fases $\delta$ e $\gamma$. O reagente é composto 
de $20 \mathrm{ml}$ de $\mathrm{HCl}$ em $80 \mathrm{ml}$ de $\mathrm{H}_{2} \mathrm{O}$ destilada $+0,3-0,6 \mathrm{~g}$ de metabissulfito de potássio com temperatura do banho entre 40 e $80^{\circ} \mathrm{C}$. A aplicação sobre a superfície foi mediante algodão embebido na solução aquecida até a superfície adquirir uma tonalidade tal como apresentada na Figura 2.

Após limpeza e secagem procedeu-se à aplicação da réplica, onde previamente, a mesma é molhada com uma solução em partes iguais de álcool e acetona e logo, colada e pressionada, manualmente, contra a superfície preparada pelo período de 1 minuto. Após desta etapa, a réplica é mantida sobre a superfície por mais 5 minutos, tal como apresentado na Figura 3, onde finalmente é cuidadosamente retirada para posterior observação em um microscópio modelo NEOPHOT 32.

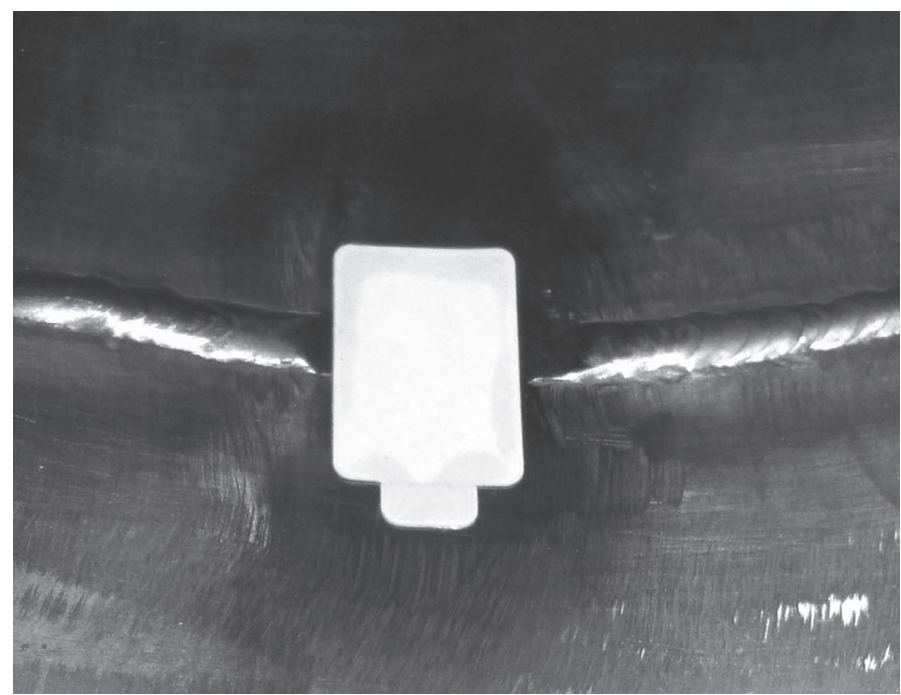

Figura 3. Superfície da junta soldada JPF2 durante aplicação da réplica.

As quantificações das fases ferrita $(\delta)$ e austenita $(\gamma)$ foram realizadas de acordo com o método de contagem manual se baseando na norma ASTM E562 [6], sendo efetuadas 30 (trinta) quantificações por condição levando em consideração diferentes aumentos.

Desta forma, uma análise comparativa foi realizada, fazendose o uso de um ferritoscópio marca Fischer MP30. Neste caso, foram efetuadas 24 (vinte quatro) medições por cada junta (MS1 e MS2) no mesmo local da realização da réplica, assim como na região adjacente (MS ADJ) à mesma de modo avaliar os resultados obtidos por ambas as metodologias de medição. As Figuras 4, 5 e 6 mostram, respectivamente, os locais de inspeção das juntas JPF4, JPF5 e JPF6, denotando que o MS1 e MS2 foram identificados, em todos os casos, em função da sua proximidade de localização com MB1 e MB2 (Tabela 3), respectivamente. Complementarmente, foram realizadas 24 medições no MB de cada componente próximo da junta de modo a determinar as diferenças de proporções de fases em relação ao MS depositado.

Finalmente, depois de realizadas todas as medições, foram efetuadas, nas juntas soldadas JPF4 e JPF5, um leve lixamento nas superfícies, com lixas de granulometria 600 e 1200 e posterior polimento com pastas de diamante de 6, 3, e $1 \mu \mathrm{m}$. Nestas condições foram levantadas novas medições da quantidade de ferrita nos diversos locais mediante uso de ferritoscópio de modo avaliar a influência de um leve lixamento nas medidas resultantes.

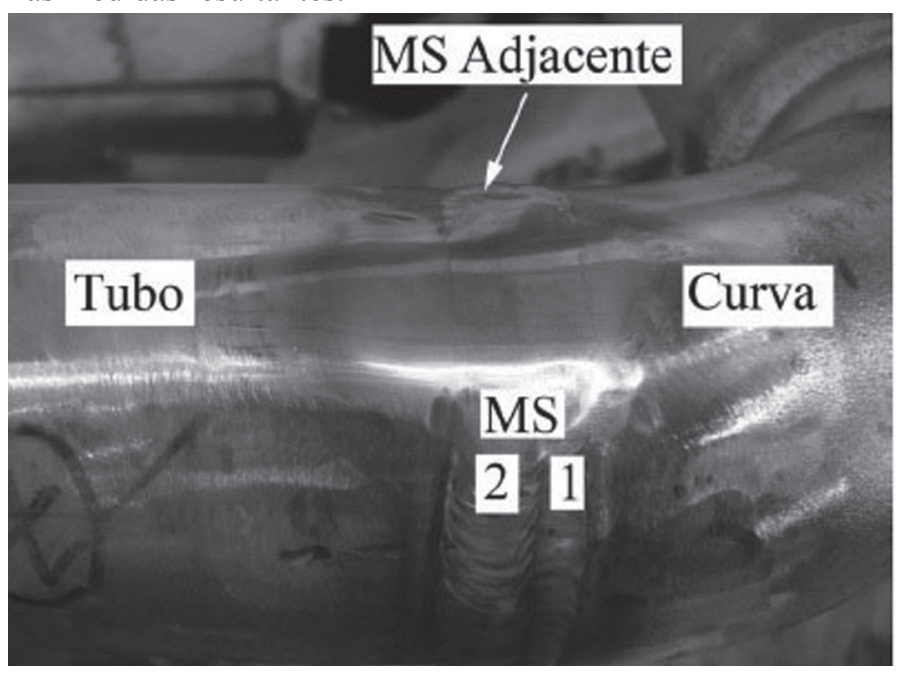

Figura 4. Locais de inspeção da junta soldada JPF4.

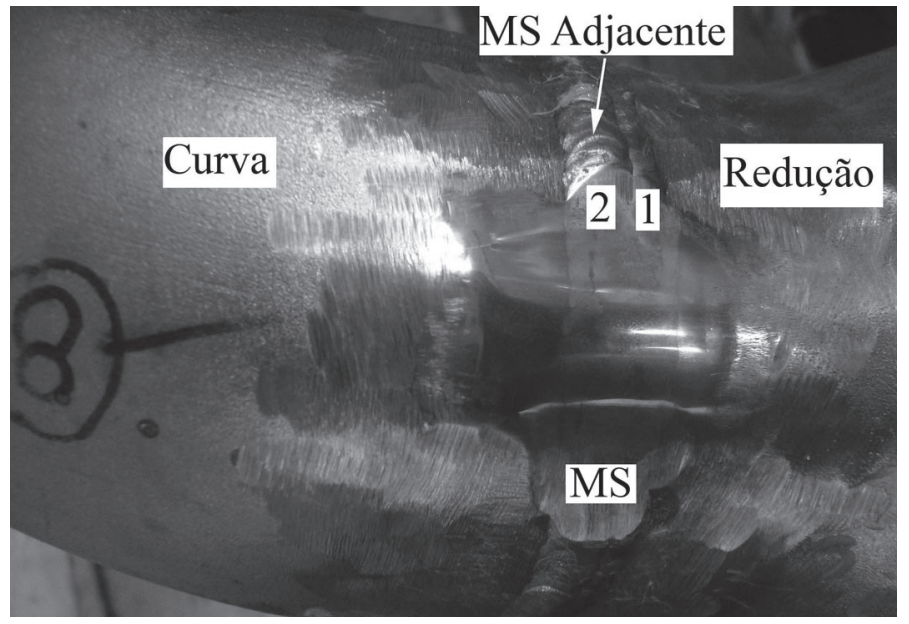

Figura 5. Locais de inspeção da junta soldada JPF5.

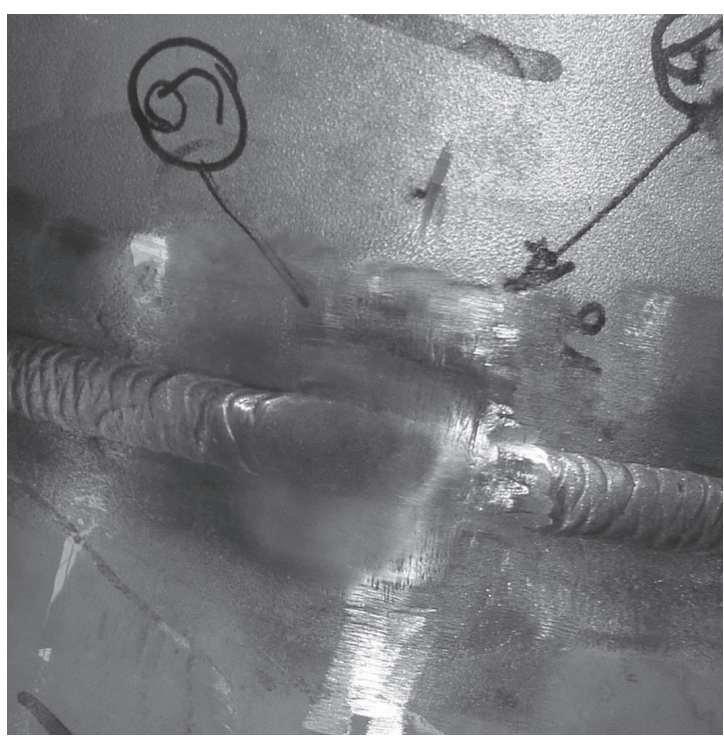

Figura 6. Locais de inspeção da junta soldada JPF6. 
(a)
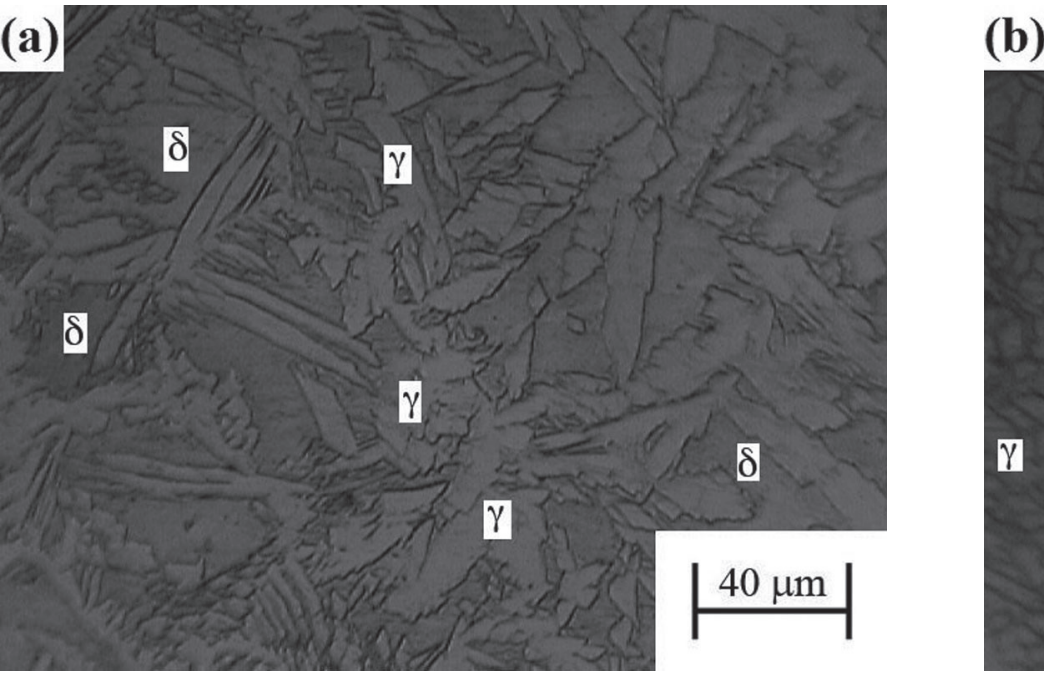

(b)
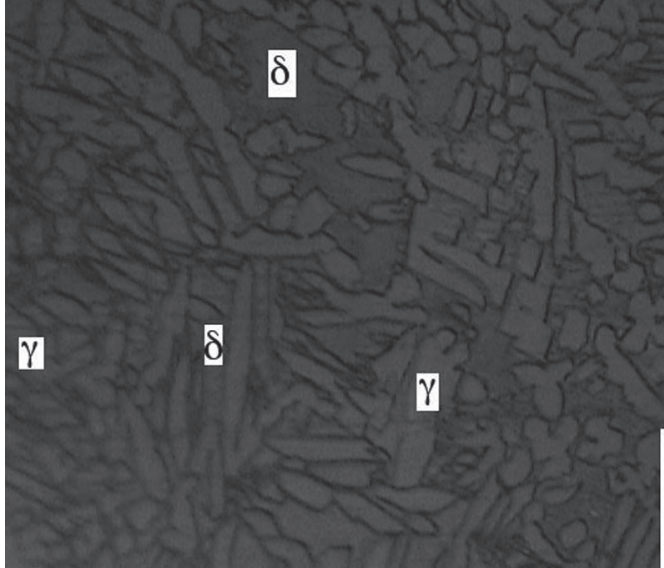

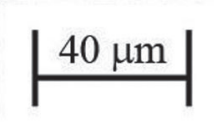

Figura 7. Microestrutura do metal de solda (MS) da JPF1 mostrando as fases $\delta$ e $\gamma$.

Figura 8. Perfil da junta JPF1 mostrando as características microestruturais da ZTA, ZL e MS.

\section{Resultados e Discussão}

A Figura 7 mostra diversos locais do metal de solda correspondente à junta soldada JPF1 observando-se claramente as fases ferrita $(\delta)$ e austenita $(\gamma)$ onde esta última fase encontrase em uma proporção maior. Através desta figura, observamse algumas austenitas de características alongadas do tipo de estrutura Widmannstätten [8], além daquelas mais equiaxiais, presentes em maior proporção na Figura 7 (b), nucleadas no interior da ferrita, seja nos nitretos de cromo previamente precipitados ou em inclusões presentes nesta fase $[9,10]$. Na Figura 8 se observa as características do perfil da junta (ZTAMS) exibindo ambos os tipos de austenita, destacando-se na zona de ligação (ZL) algumas austenitas de características alotriomorfas $\left(\gamma_{\mathrm{a}}\right)$ na ZTA de temperatura elevada (ZTATE) tal como reportado por Ramirez Londoño [9].

Assim como apresentado na Figura 7, a Figura 9, correspondente ao metal de solda da junta soldada JPF2, exibe os tipos de austenita Widmannstätten e, principalmente, aquela oriunda de nitretos de tamanho grosseiro cujo crescimento originou-se provavelmente por difusão pela permanência do MS em altas temperaturas. $\mathrm{O}$ fenômeno de uma maior proporção de austenita precipitada pode ser decorrente da utilização simultânea de nitrogênio no gás de proteção, consumível com alto teor de níquel, aportes de calor e temperaturas interpasse no limite superior de faixa estabelecida para AID.

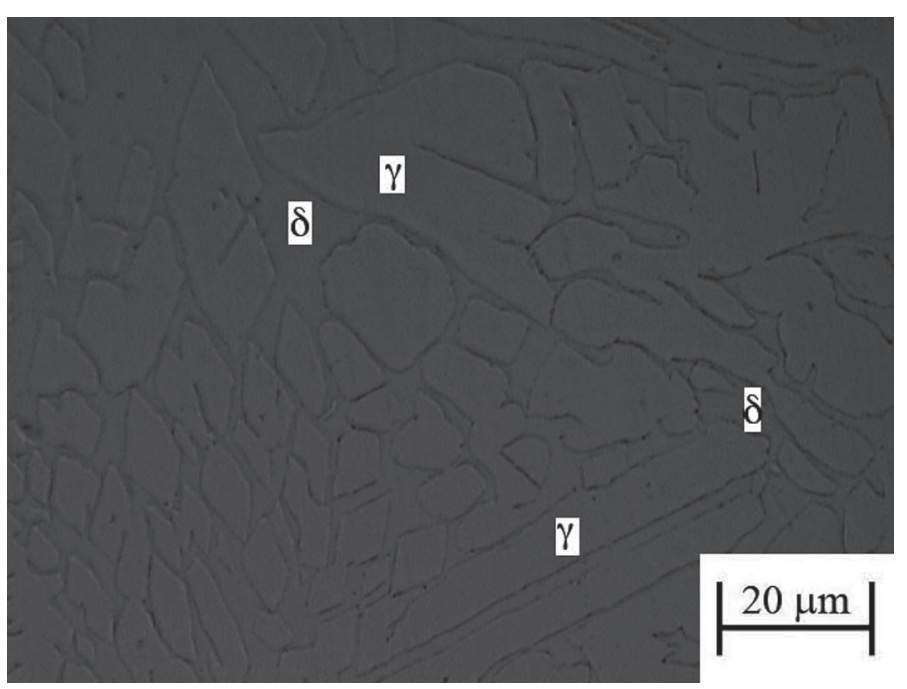

Figura 9. Microestrutura do metal de solda (MS) da JPF2 mostrando as fases $\delta$ e $\gamma$. 

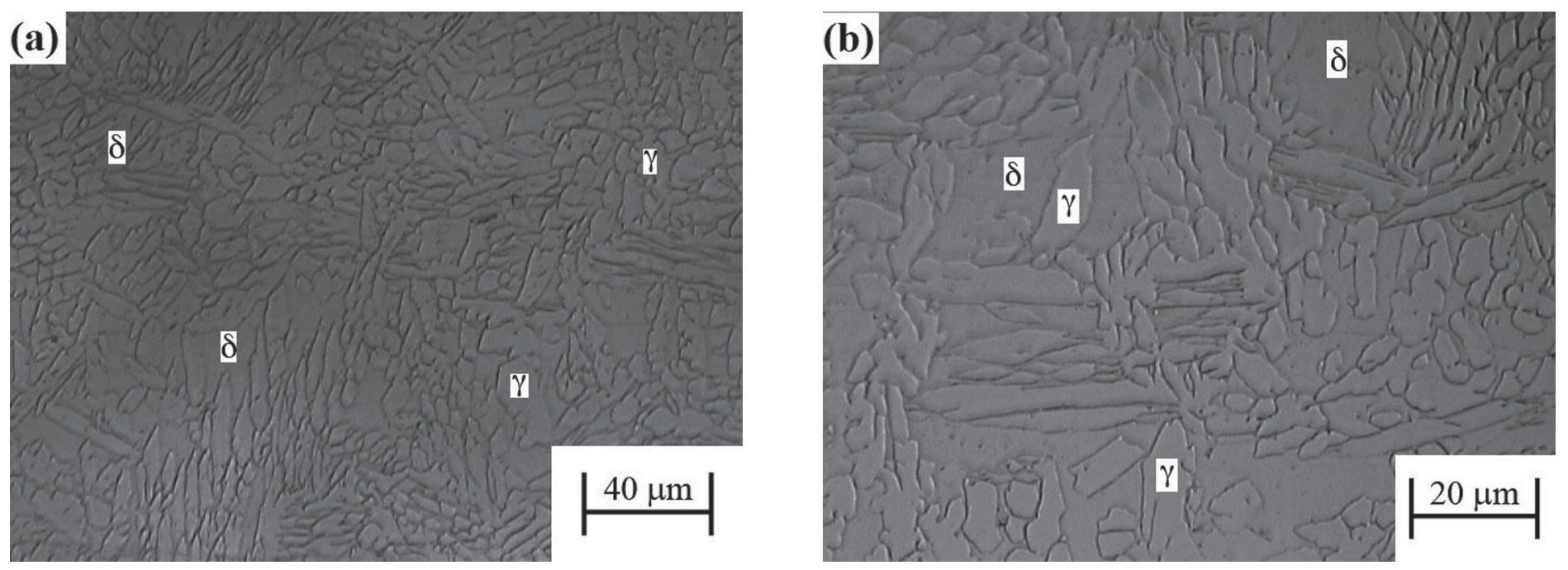

Figura 10. Microestrutura do metal de solda (MS) da JPF3 mostrando as fases $\delta$ e $\gamma$.

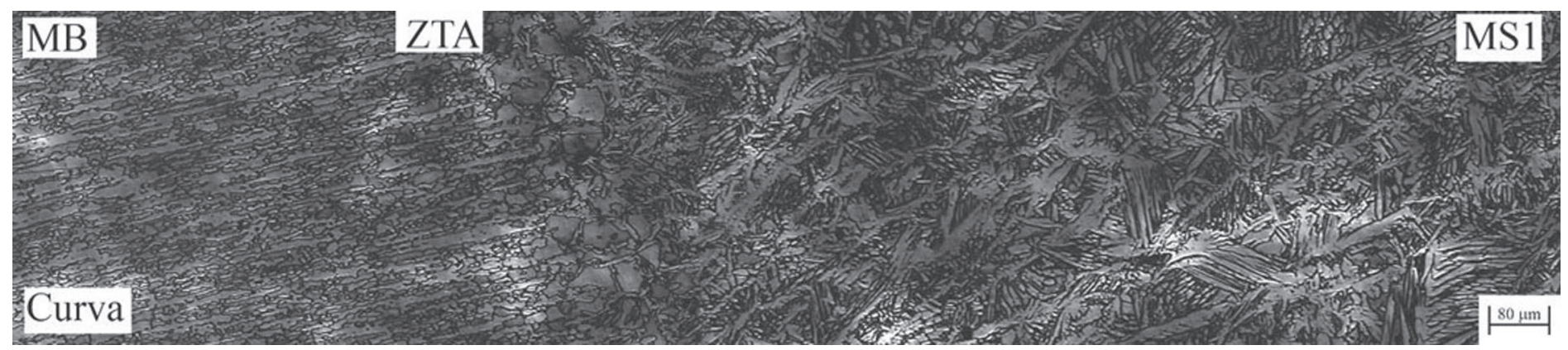

Figura 11. Perfil da junta JPF4 mostrando as características microestruturais do MB1, ZTA, ZL e MS1.
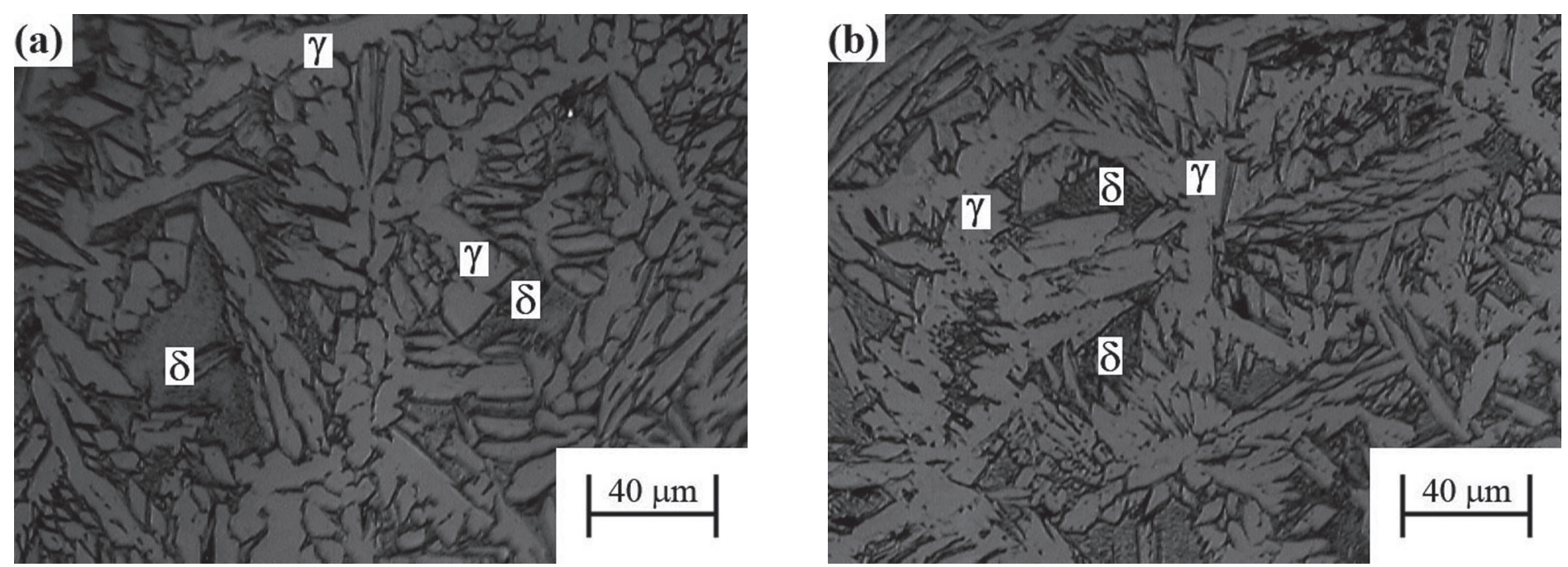

Figura 12. Microestrutura do metal de solda (MS) da JPF4 mostrando as fases $\delta$ e $\gamma$.

A réplica correspondente à junta soldada JPF3 é apresentada na Figura 10 com diversos aumentos exibindo as mesmas características das anteriormente descritas.

A Figura 11 mostra a microestrutura obtida para o perfil da junta soldada JPF4 do lado do MB1 correspondente à curva, denotando um forte refino microestrutural do MB1 em comparação com o metal de solda composto por uma maior proporção de austenita com características de Widmannstätten e daquelas decorrentes de precipitados intragranulares da ferrita de tamanho grosseiras, tal como mostra a Figura $12 \mathrm{em}$ diversas regiões. Entretanto, na Figura 11 podem ser observadas algumas austenitas de características alotriomorfas precipitadas na ZTATE da junta. Cabe salientar, que este tipo de austenita, pode ser detectado em AID durante resfriamentos bruscos desde temperaturas de pico da ordem de $1200-1300^{\circ} \mathrm{C}$.

A Figura 13 exibe o perfil de solda na zona de ligação do 


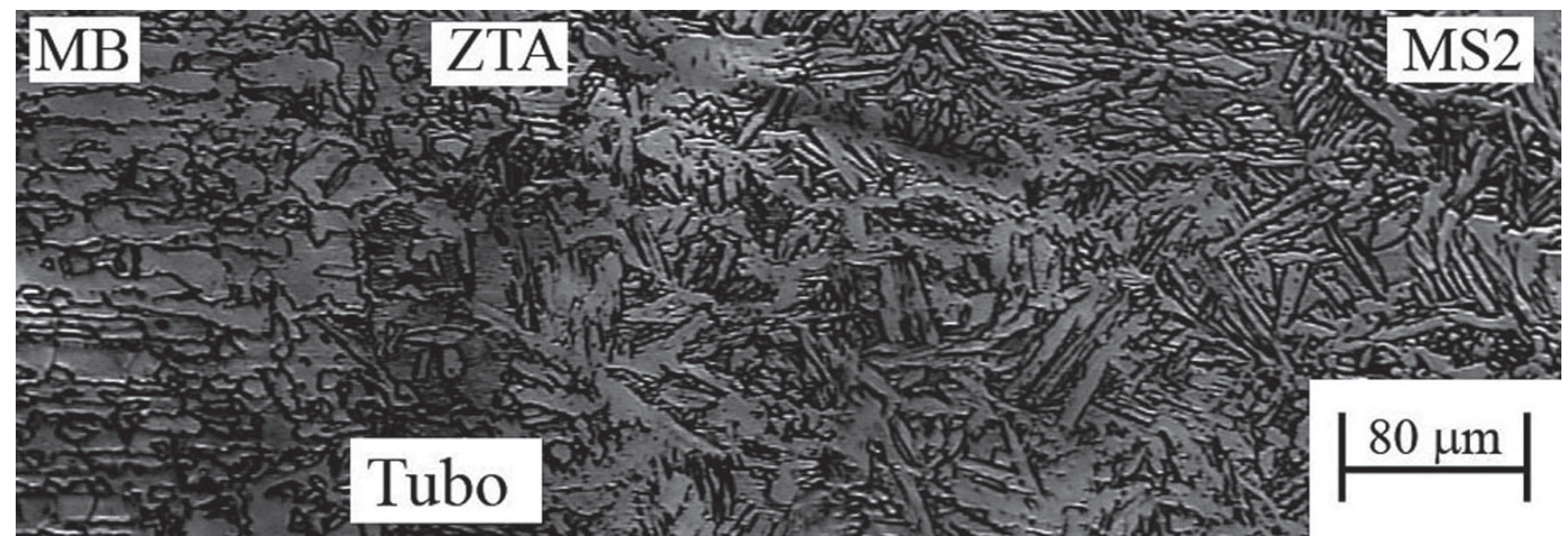

Figura 13. Perfil da junta JPF4 mostrando as características microestruturais do MB2, ZTA, ZL e MS2

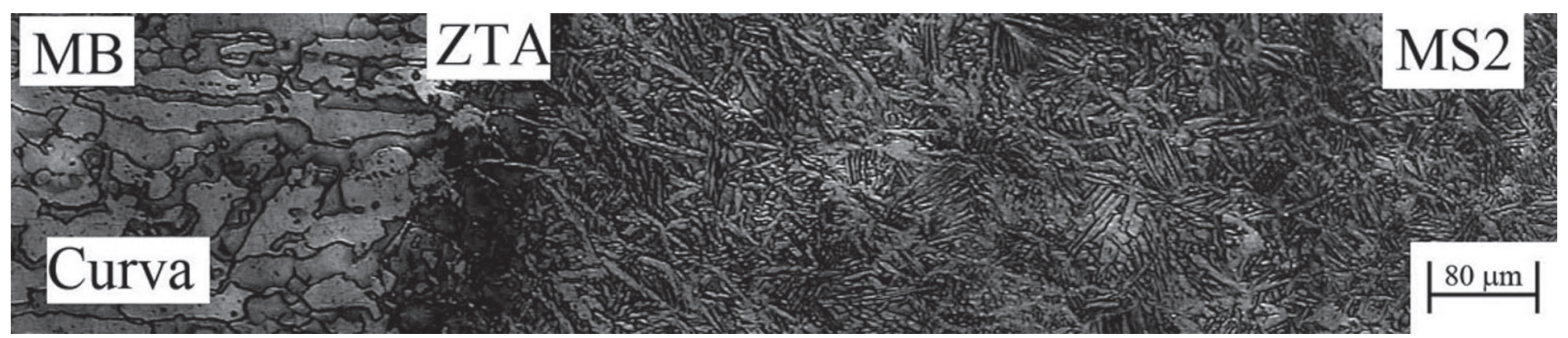

Figura 14. Perfil da junta JPF5 mostrando as características microestruturais do MB2, ZTA, ZL e MS2.

(a)

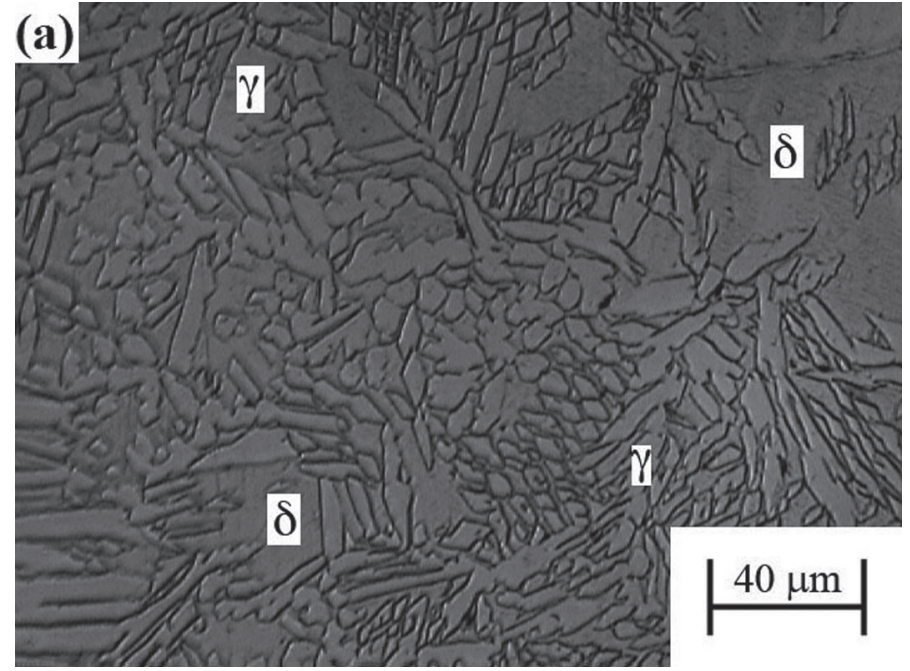

(b)

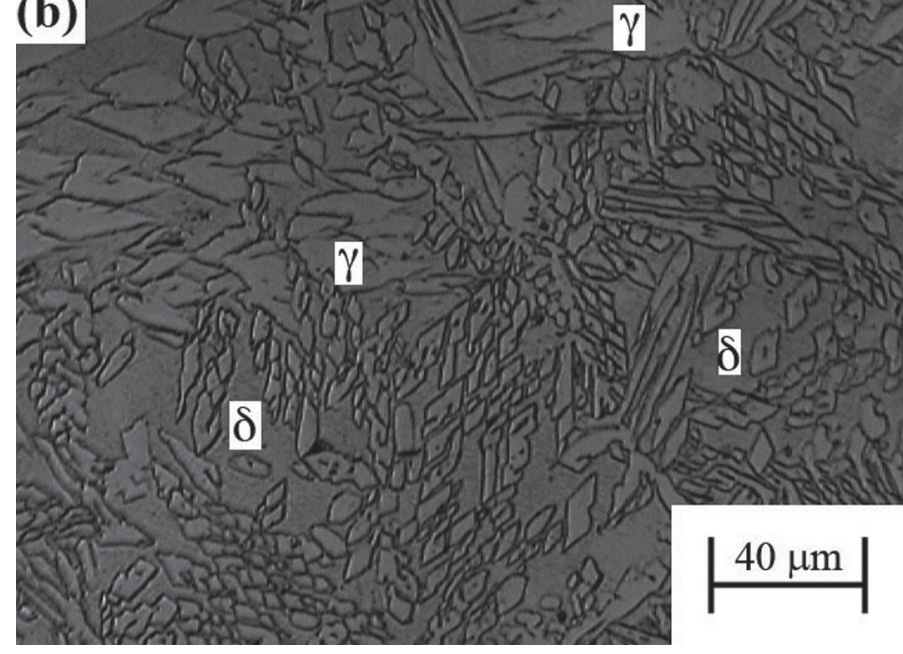

Figura 15. Microestrutura do MS1 da JPF5 mostrando as fases $\delta$ e $\gamma$.

tubo com o MS2 da JPF4 denotando uma grande proporção de austenita no MS2.

A Figura 14 mostra a réplica correspondente à ZL do MS2 da junta soldada JPF5 mostrando, assim como as demais condições analisadas, uma forte precipitação de austenita, embora se observe, na ZTATE, algumas austenitas alotriomorfas contendo grãos grosseiros de ferrita em virtude de esta região experimentar temperaturas elevadas que favorecem à formação de $\delta$.

A Figura 15 exibe as microestruturas em diferentes regiões do MS1 da junta JPF5 destacando-se uma maior proporção de austenita com preponderância de precipitação daquelas oriundas de precipitados e inclusões intragranulares da ferrita em decorrência de uma baixa velocidade de resfriamento.

A Figura 16 exibe o perfil circunferencial ao longo da solda de acabamento (MS2) da junta JPF5 denotando-se claramente que em aproximadamente $0,5 \mathrm{~mm}$ há uma mudança substancial da proporção e dos tipos de austenita precipitadas como provável conseqüência da variação do aporte de calor em decorrência 


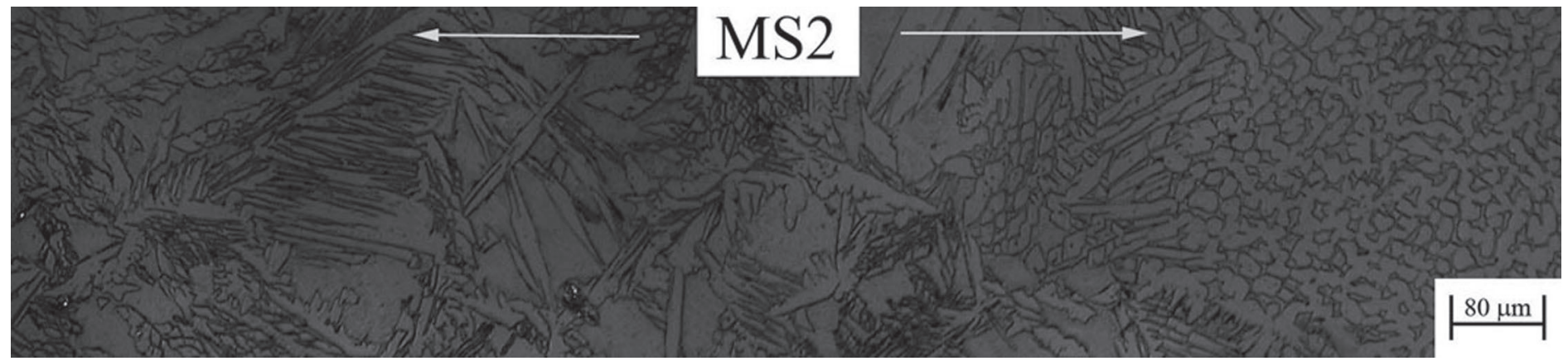

Figura 16. Metal de solda (MS2) da JPF5. Perfil ao longo do cordão solda (MS2). Variação de morfologia e da proporção de fases ao longo de um pequeno comprimento da junta.
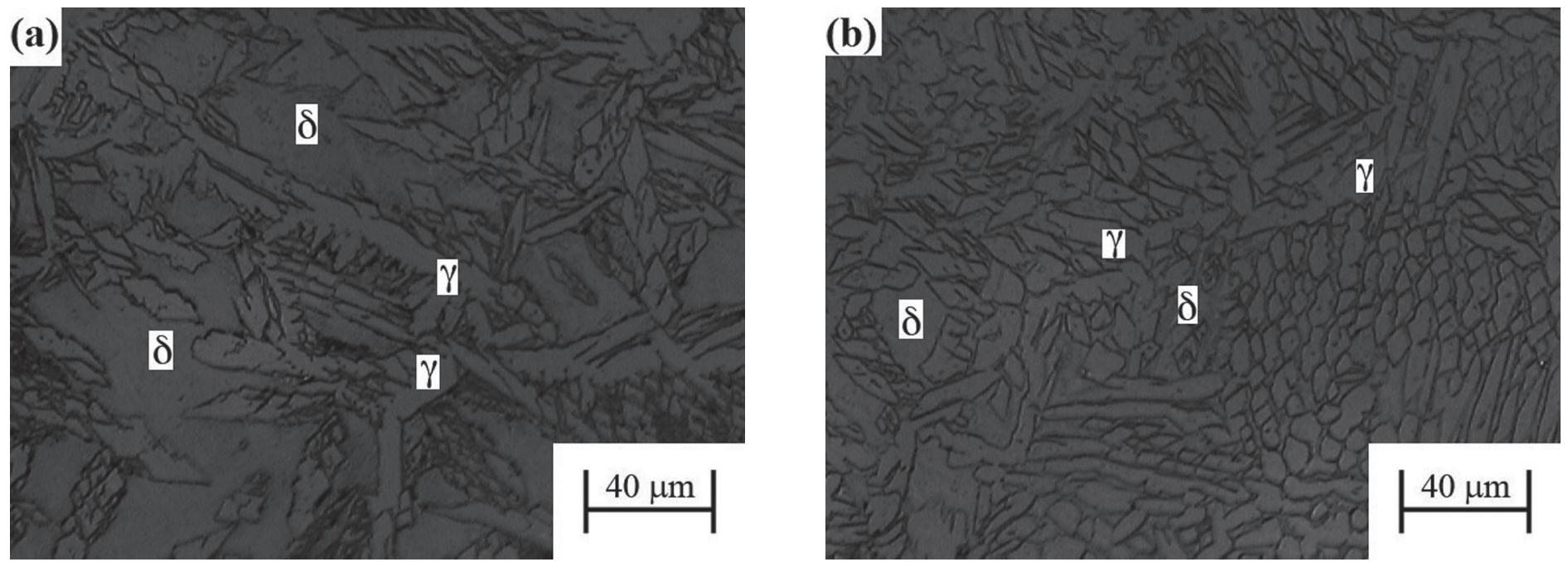

Figura 17. Microestruturas do MS2 da JPF5. Preponderância de precipitação de austenita (a) Widmannstätten (b) oriunda de nitretos de cromo $\left(\mathrm{Cr}_{2} \mathrm{~N}\right)$.

\section{(a)}

$\gamma$

\section{$\gamma$}

$\delta$

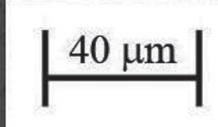

$\delta$

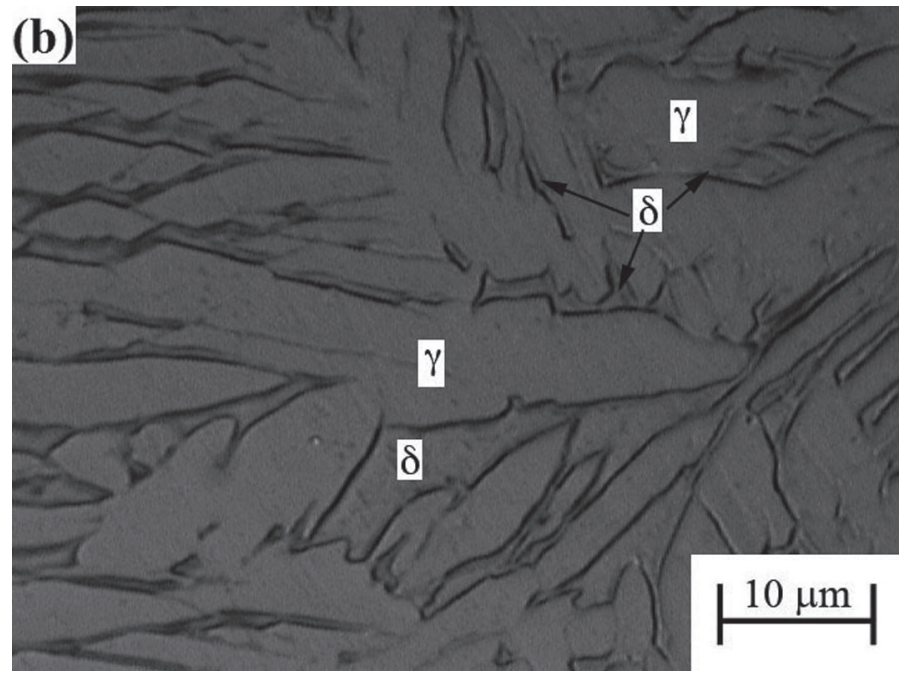

Figura 18. Microestrutura do MS1 da JPF6 mostrando as fases $\delta$ e $\gamma$.

da mudança da velocidade de soldagem. Na esquerda do perfil de solda, também apresentado na Figura 17 (a) com maiores aumentos, se observa preponderantemente austenita do tipo Widmannstätten com elevada quantidade de ferrita em virtude de uma maior velocidade de avanço da tocha de soldagem. Cabe destacar que este tipo de austenita é resultante de elevadas velocidades de resfriamento se comparada com a oriunda de nitretos de cromo. Entretanto, na direita do perfil, também observado com maiores aumentos na Figura 17 (b), se observam preponderantemente austenita do tipo equiaxial grosseira provavelmente atribuída a um mecanismo de difusão por permanências em altas temperaturas como produto de uma 
baixa velocidade de avanço da tocha GTAW. Como era de se esperar, neste último caso a proporção de ferrita é muito baixa se comparada com a região da esquerda do perfil. Deste modo existirá uma grande influência das medidas obtidas por PM pelo uso do ferritoscópio nestes locais.

A Figura 18 mostra as características microestruturais obtidas no MS da junta soldada JPF6 com diferentes aumentos observando-se claramente, na imagem da Figura 18 (b), obtida com aproximadamente $3800 \mathrm{X}$, que as austenitas precipitadas, em maior proporção, cresceram por difusão por um elevado tempo de permanência em altas temperaturas. Este fato pode ser atribuído à realização de um único passe de acabamento para fechamento da junta dando lugar a um tecimento longo que poderia ter acarretado em uma diminuição da velocidade de soldagem. Além disso, para se obter uma maior taxa de deposição, com uma conseqüente maior produtividade, pode ter sido utilizado um eletrodo não consumível de tungstênio - tória de maior diâmetro de modo efetuar um único passe de acabamento da tubulação de $273,1 \mathrm{~mm}$ de diâmetro externo e 4,2 $\mathrm{mm}$ de espessura, conforme indicado na Tabela 3.
A Tabela 4 mostra os valores levantados de ferrita $(\delta)$ pelas quantificações mediante uso da réplica por microscopia óptica indireta (MOI) e pelo uso do ferritoscópio (PM) obtendo-se, em todos os casos, valores próximos. Denota-se, portanto, que as medidas obtidas pelo uso do ferritoscópio em superfícies previamente preparadas resultaram em valores confiáveis de medição. Salienta-se ainda que a correlação existente entre as medidas obtidas por MOI e PM foi analisada para soldas com teor de ferrita próximos do valor limite inferior admissível em MS de AID. No entanto, esta análise deverá ser também realizada para metais de solda com teores maiores de ferrita em virtude de que a calibração do instrumento ter sido efetuada em os blocos fornecidos pelo fabricante, tendo como valor máximo um $30,3 \%$ de ferrita, comparável com os valores obtidos nos metais de solda das juntas analisadas. Deste modo, sugere-se a realização de padrões de calibração de MS de AID para o uso do ferritoscópio com diferentes teores de ferrita precipitada de modo a se obter uma maior precisão nos resultados, tendo em vista de que podem existir outros fatores que influenciem na

Tabela 4. Valores de MOI e PM levantados para cada junta.

\begin{tabular}{|c|c|c|c|c|c|}
\hline Junta & Local & Diâmetro Externo (mm) & Posição & MOI $(\%)$ & PM $(\%)$ \\
\hline \multirow{5}{*}{ JPF1 } & \multirow{5}{*}{ Acabamento } & \multirow{5}{*}{323,9} & MB1 & $\begin{array}{ll}----- \\
\end{array}$ & $49,18 \pm 1,43$ \\
\hline & & & MS1 & \multirow{2}{*}{$38,01 \pm 2,55$} & $36,18 \pm 1,83$ \\
\hline & & & MS2 & & $42,81 \pm 1,39$ \\
\hline & & & MS2ADJ & $\begin{array}{ll}----- \\
\end{array}$ & $32,96 \pm 2,00$ \\
\hline & & & MB2 & $\begin{array}{ll}----- \\
\end{array}$ & $38,17 \pm 0,40$ \\
\hline \multirow{4}{*}{ JPF2 } & \multirow{4}{*}{ Raiz } & \multirow{4}{*}{323,9} & MB1 & ------ & $48,61 \pm 1,45$ \\
\hline & & & MS & $33,56 \pm 3,22$ & $36,70 \pm 0,80$ \\
\hline & & & MSADJ & $\begin{array}{ll}----- \\
\end{array}$ & $27,93 \pm 1,06$ \\
\hline & & & MB2 & ------ & $41,16 \pm 0,42$ \\
\hline \multirow{5}{*}{ JPF3 } & \multirow{5}{*}{ Acabamento } & \multirow{5}{*}{88,9} & MB1 & $\begin{array}{ll}----- \\
\end{array}$ & $44,03 \pm 2,02$ \\
\hline & & & MS1 & \multirow{2}{*}{$40,00 \pm 5,31$} & $38,58 \pm 0,87$ \\
\hline & & & MS2 & & $36,05 \pm 0,93$ \\
\hline & & & MS2ADJ & $\begin{array}{ll}----- \\
\end{array}$ & $35,38 \pm 3,30$ \\
\hline & & & MB2 & $\begin{array}{ll}----- \\
\end{array}$ & $48,63 \pm 1,49$ \\
\hline \multirow{5}{*}{ JPF4 } & \multirow{5}{*}{ Acabamento } & \multirow{5}{*}{60,3} & MB1 & $\begin{array}{ll}---- \\
--1\end{array}$ & $45,60 \pm 0,84$ \\
\hline & & & MS1 & $32,82 \pm 3,08$ & $31,88 \pm 0,70$ \\
\hline & & & MS2 & $35,09 \pm 2,92$ & $33,21 \pm 0,36$ \\
\hline & & & MS2ADJ & ------ & $30,15 \pm 1,79$ \\
\hline & & & MB2 & ------ & $41,50 \pm 0,65$ \\
\hline \multirow{5}{*}{ JPF5 } & \multirow{5}{*}{ Acabamento } & \multirow{5}{*}{88,9} & MB1 & $\begin{array}{ll}----- \\
\end{array}$ & $43,70 \pm 0,43$ \\
\hline & & & MS1 & $37,78 \pm 3,99$ & $36,44 \pm 1,35$ \\
\hline & & & MS2 & $39,17 \pm 4,43$ & $37,20 \pm 1,27$ \\
\hline & & & MS2ADJ & $\begin{array}{l}----- \\
\end{array}$ & $31,55 \pm 1,70$ \\
\hline & & & MB2 & ------ & $50,22 \pm 0,86$ \\
\hline \multirow{4}{*}{ JPF6 } & \multirow{4}{*}{ Acabamento } & \multirow{4}{*}{273,1} & MB1 & ------ & $42,36 \pm 1,40$ \\
\hline & & & MS & $28,01 \pm 3,33$ & $33,38 \pm 0,70$ \\
\hline & & & MSADJ & $\begin{array}{l}----- \\
\end{array}$ & $32,60 \pm 3,25$ \\
\hline & & & MB2 & ----- & $43,32 \pm 3,89$ \\
\hline
\end{tabular}


Tabela 5. Valores de PM levantados antes (PMA) e depois (PMD) do lixamento nas JPF4 e JPF5.

\begin{tabular}{|l|l|l|l|l|l|}
\hline Junta & Local & Diâmetro Externo (mm) & Posição & PMA (\%) & PMD (\%) \\
\hline \multirow{5}{*}{ JPF4 } & \multirow{3}{*}{ Acabamento } & \multirow{2}{*}{88,9} & MB1 & $45,60 \pm 0,84$ & $46,52 \pm 0,29$ \\
\hline & & MS1 & $31,88 \pm 0,70$ & $31,83 \pm 0,69$ \\
\hline & & MS2 & $33,21 \pm 0,36$ & $33,63 \pm 0,71$ \\
\hline \multirow{5}{*}{ JPF5 } & \multirow{3}{*}{ Acabamento } & \multirow{2}{*}{273,1} & MB2 & $41,50 \pm 0,65$ & $41,03 \pm 0,34$ \\
\hline & & MB1 & $43,70 \pm 0,43$ & $44,34 \pm 0,52$ \\
\hline & & MS1 & $36,44 \pm 1,35$ & $36,44 \pm 2,01$ \\
\hline & & MS2 & $37,20 \pm 1,27$ & $37,88 \pm 1,64$ \\
\hline & & MB2 & $50,22 \pm 0,86$ & $48,86 \pm 0,65$ \\
\hline
\end{tabular}

medição tal como orientação preferencial e tamanho dos grãos das fases analisadas [11].

$\mathrm{Na}$ Tabela 4 ainda foram acrescentados os valores de proporção de ferrita obtidos na região adjacente à da inspeção sobre o metal de solda MS2 (MS2ADJ) denotando que todos os valores obtidos nestas condições são menores à da região de inspeção. Estas diferenças são principalmente produto da convexidade do reforço da solda, tendo em vista que o principio de funcionamento correto do ferritoscópio, tal como apresentado na Figura 19, se baseia em um campo magnético gerado por uma bobina que interage que com a(s) fase(s) magnética(s) da amostra [12]. Logo, se algumas linhas do campo magnético, geradas pela corrente primária de excitação, não atravessam o material, a excitação das fases ferromagnéticas da superfície da amostra será insuficiente, induzindo-se, portanto uma voltagem menor na bobina secundaria correspondente ao sinal de medição, ou seja, será registrado um menor teor de ferrita. Por este motivo, são estabelecidos, pelo fabricante do equipamento, fatores de correção nas medições efetuadas principalmente em função das características geométricas da superfície de medição [13]. Deste modo, quanto mais convexo for o reforço da junta, menor será o teor de ferrita que o ferritoscópio irá a registrar. Tal fato é observado na raiz da solda da JPF2, da Figura 3, em que a convexidade do cordão é maior se comparada às convexidades de acabamento das juntas estudadas. Neste caso, conforme a Tabela 4, a diferença percentual entre MS e MSADJ resultou mais significativa em relação das demais condições analisadas.

Conforme mostrado na Tabela 5, o efeito do lixamento manual, com lixa de granulometria 600 e 1200, entre medições praticamente não teve influência nos valores levantados por PM. Neste contexto, o efeito de formação de martensita, de características magnéticas, induzida por alguma microdeformação plástica sob a superfície é nula em virtude da austenita do AID apresentar elevada energia de falha de empilhamento (EFE) [14]. No entanto, lixamentos mediante uso de microretifica com lixas de grãos mais grosseiros devrão ser realizados de modo avaliar a sua possível influência em condições mas exigentes.

A análise por meio de réplicas mostra-se viável em alguns casos em virtude de que, além de ser um ensaio com documentação de registro, podem ser analisadas as características microestruturais e proporções das fases precipitadas em pequenos trechos de comprimento e/ou largura da junta. Em

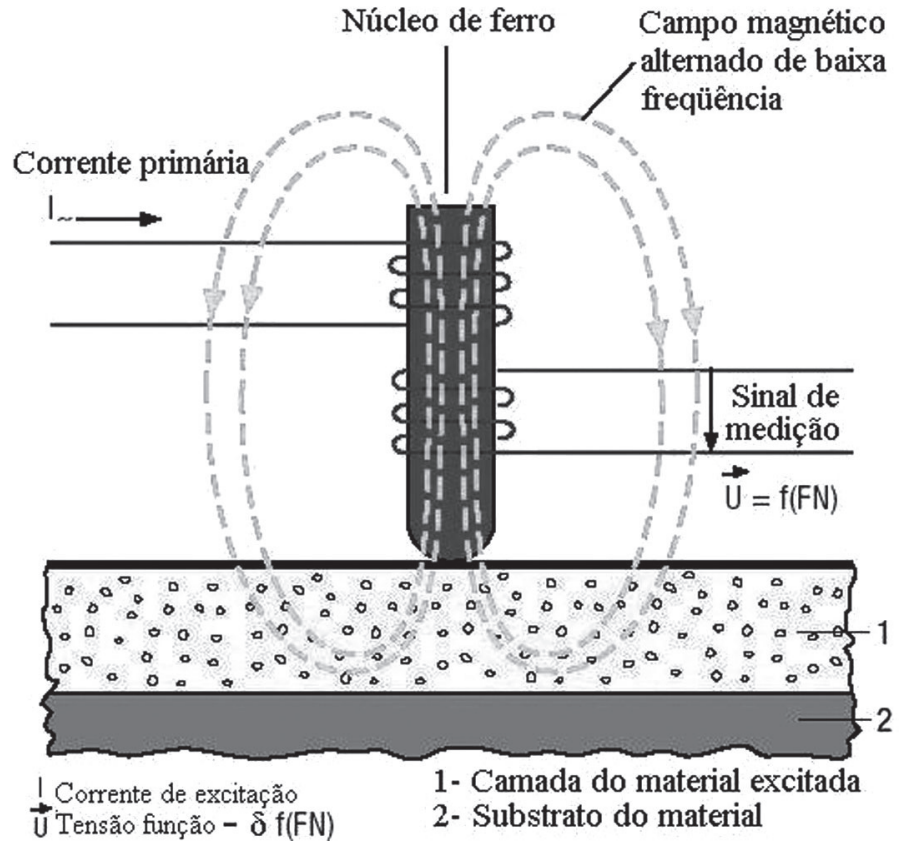

Figura 19. Principio de funcionamento do ferritoscópio [12].

contrapartida, além de ser um exame de avaliação superficial, requer pessoal treinado, tendo resultados conclusivos após tempo de estudo, mediante análise laboratorial e conduzindo a uma baixa produtividade na inspeção. No entanto, torna-se interessante o estudo complementar no local de análise com uso de réplicas de juntas soldadas de AID no caso de obterem valores que estejam próximos do valor crítico e/ou com bastante dispersão por meio do uso do ferritoscópio tal como mostrado na Figura 16 para o MS2 da JPF5.

Conclui-se, portanto, que a região avaliada deverá ser delimitada por uma determinada área que deverá possuir suficiente planicidade, além de serem efetuadas, nesta região, pelo menos 24 medições pelo uso do ferritoscópio. Neste sentido seria interessante a criação de uma instrução normativa de inspeção, mais rigorosa, baseada nestes critérios.

\section{Conclusões}

O presente estudo permite concluir que:

1. As proporções de ferrita $(\delta)$ obtidas pelo uso do ferritoscópio, 
em superfícies previamente preparadas, resultaram próximas às obtidas por MOI mediante uso de réplicas metalográficas em juntas soldadas contendo aproximadamente teores de ferrita entre 30 e 40\%. No entanto, é aconselhável a realização de blocos de calibração de MS depositado com diversas proporções de ferrita / austenita de modo obter uma maior precisão nos valores adquiridos.

2. As medições das proporções de fases mediante uso do ferritoscópio sobre o MS sem tratamento prévio da superfície acusará valores percentuais menores de ferrita em virtude da convexidade do cordão.

3. O efeito do lixamento entre medições praticamente não teve influência nos valores levantados por PM mediante uso do ferritoscópio.

4. Caso as medições de proporções de fases mediante uso do ferritoscópio estiverem próximas do valor crítico e/ou com bastante dispersão, torna-se indispensável um estudo complementar mediante emprego de réplicas metalográficas no local de análise de modo a determinar mudanças microestruturais e de proporções de fases no local de análise.

5. A região avaliada deverá ser delimitada por uma determinada área que deverá possuir planicidade suficiente, além de serem efetuadas, nesta região, pelo menos 24 medições pelo uso do ferritoscópio. Neste sentido seria interessante a criação de uma instrução normativa de inspeção, mais rigorosa, baseada nestes critérios.

\section{Referências Bibliográficas}

[1] MUTHUPANDI, V.; BALA SRINIVASAN, P.; SESHADRI, S.K., SUNDARESAN S. Effect of Weld Metal Chemistry and Heat Input on the Structure and Properties of Duplex Stainless Steel Welds. Materials Science and Engineering. Vol. A358 (2003). 9-16, 2003.

[2] REICK, W.; POHL, M.; PADILHA, A.F. O desenvolvimento dos aços inoxidáveis ferríticos-austeníticos com microestrutura duplex. In: CONGRESSO ANUAL DA ABM, 47. 1992, Belo Horizonte. Vol 48, No409.

[3] NORSOK STANDARD M-601: Welding and Inspection of Piping. Rev. 4, July 2004.

[4] PARDAL, J.M.; TAVARES, S.S.M.; FARIA, R.A. Aços inoxidáveis Duplex (austeno-ferríticos) microestrutura e propriedades. Metalurgia \& Materiais. 2008; 64: 624-626.

[5] TAVARES, S.S.M.; PARDAL, J.M.; GUERREIRO, J.L., GOMES, A.M.; DA SILVA, M.R. Magnetic detection of sigma phase in duplex stainless steel UNS S31803. Journal of Magnetism and Magnetic Materials. Vol. 322 (2010). L29-L33, 2010.

[6] ASTM E562-05: Standard Test Method for Determining Volume Fraction by Systematic Manual Point Count.

[7] PARDAL, J.M.; TAVARES, S.S.M.; CINDRA FONSECA, M.P.; SOUZA, J.A., COSTA, V.C.; FERREIRA, M.L.R.; D'AVILA, C.R. Caracterização e quantificação das fases precipitadas por réplicas metalográficas no aço inoxidável superduplex. In: $10^{\circ}$ Coteq. Salvador, Bahia. 2009.

[8] GUNN, R.N. Duplex stainless steels. Microstructure, properties and applications. Cambridge - England: Abington
Publishing, 2003. 204 p.

[9] RAMÍREZ LONDOÑO, A.J. Precipitação de fases intermetálicas e austenita secundária na ZAC de soldagens multipasse de aços inoxidáveis duplex. Tese de doutorado, Escola Politécnica da Universidade de São Paulo, 2001.

[10] RAMIREZ, A.J.; LIPPOLD, J.C.; BRANDI, S.D. The Relationship Between Chromium Nitride and Secondary Austenite Precipitation in Duplex Stainless Steels. Metallurgical and Materials Transactions A. Vol. 34A. 1575-1597, 2003.

[11] PARDAL, J.M.; TAVARES, S.S.M.; CINDRA FONSECA, M.P.; SOUZA, J.A., OLIVEIRA, T.R.; ABREU, H.F.G.; DA SILVA, M.R. Estudo da quantificação de fases deletérias utilizando medições magnéticas no aço inoxidável superduplex UNS S32750. Revista ABENDI. N³8. 50-55. Junho de 2010.

[12] HELMUT FISCHER. Measurement of the ferrite content in austenitic and duplex steel. Helmut Fischer - Germany. Catálogo do Feritscope ${ }^{\circledR}$ MP30. Disponível em: < http://www.helmutfischer.com/globalfiles/DE_MP30Fe EN_0902.pdf $>$. Acesso em: 15 Jun. 2012.

[13] HELMUT FISCHER. Operator's Manual. Feritscope $\mathbb{}$ MP30E-S and MP30E-R. Version 2.2. September 2006.

[14] TAVARES, S.S.M.; DA SILVA, M.R.; PARDAL, J.M; ABREU, H.F.G.; GOMES, A.M. Microstructural Changes Produced by Plastic Deformation in the UNS S31803 Duplex Stainless Steel. Journal of Materials Processing Technology. Vol. 180 (2006). 318-322, 2006. 